\title{
Erratum to: Composition of Anopheles mosquitoes, their blood-meal hosts, and Plasmodium falciparum infection rates in three islands with disparate bed net coverage in Lake Victoria, Kenya
}

Edwin Ogola ${ }^{1,2}$, Jandouwe Villinger ${ }^{1 *} \mathbb{C}$, Danspaid Mabuka ${ }^{1}$, David Omondi ${ }^{1,2}$, Benedict Orindi $^{1}$, James Mutunga' ${ }^{1}$ Vincent Owino ${ }^{1,2}$ and Daniel K. Masiga'

\section{Erratum to: Malar J (2017) 16:360}

DOI 10.1186/s12936-017-2015-5

After publication of the article [1], it has been brought to our attention that a funding acknowledgement has been omitted from the original article. The authors would like to include the following, "The study was undertaken as part of the Target Malaria consortium, which receives core funding from the Bill \& Melinda Gates Foundation \& from the Open Philanthropy Project Fund, an advised fund of Silicon Valley Community Foundation."

\section{Author details}

${ }^{1}$ International Centre of Insect Physiology and Ecology (icipe), P.O. Box 30772, Nairobi 00100, Kenya. ${ }^{2}$ Department of Biochemistry and Molecular Biology, Egerton University Njoro Campus, P.O. Box 536, Egerton 20115, Kenya.

\section{Publisher's Note}

Springer Nature remains neutral with regard to jurisdictional claims in published maps and institutional affiliations.

Received: 13 September 2017 Accepted: 13 September 2017

Published online: 19 September 2017

\section{Reference}

1. Ogola E, Villinger J, Mabuka D, Omondi D, Orindi B, Mutunga J, Owino V. Masigal DK. Composition of Anopheles mosquitoes, their blood-meal hosts, and Plasmodium falciparum infection rates in three islands with disparate bed net coverage in Lake Victoria, Kenya. Malaria J. 2017;16:1 . doi:10.1186/s12936-017-2015-5.

\footnotetext{
${ }^{*}$ Correspondence: jandouwe@icipe.org

${ }^{1}$ International Centre of Insect Physiology and Ecology (icipe), P.O.

Box 30772, Nairobi 00100, Kenya

Full list of author information is available at the end of the article
} provided you give appropriate credit to the original author(s) and the source, provide a link to the Creative Commons license, and indicate if changes were made. The Creative Commons Public Domain Dedication waiver (http://creativecommons.org/ publicdomain/zero/1.0/) applies to the data made available in this article, unless otherwise stated. 